\title{
Sistem Kendali Penghindar Rintangan Pada Quadrotor Menggunakan Konsep Linear Quadratic
}

\author{
Ariesa Budi Zakaria*1, Andi Dharmawan ${ }^{2}$ \\ ${ }^{1}$ Prodi S1 Elektronika dan Instrumentasi, FMIPA UGM, Yogyakarta, Indonesia \\ ${ }^{2}$ Departemen Ilmu Komputer dan Elektronika, FMIPA UGM, Yogyakarta, Indonesia \\ e-mail: *1. ${ }^{1}$ riesabudizakaraia@gmail.com, ${ }^{2}$ dharmawan.andi@ gmail.com
}

\begin{abstract}
Abstrak
Quadrotor adalah salah satu jenis UAV (Unmanned Aerial Vehicle) dengan sayap putar (rotary wing). Quadrotor sudah banyak digunakan untuk berbagai kebutuhan militer maupun sipil. Quadrotor dapat dioperasikan dari jarak jauh secara manual atau secara otonom. Salah satu kesulitan dalam mengoperasikan quadrotor adalah menghindari rintangan saat terbang menuju suatu titik tujuan secara otonom.

Sistem kendali penghindar rintangan yang dirancang dan dibuat dalam penelitian ini menggunakan metode Linear Quadratic Regulator (LQR). LQR merupakan sistem kendali yang menghasilkan nilai masukan sistem yang diperoleh dari nilai state dan feedback, nilai state terdiri dari translasi dan rotasi. Nilai masukan tersebut dikonversi menjadi Pulse Width Modulation untuk mengendalikan kecepatan motor brushless, sehingga dapat melakukan manuver menghindari rintangan.

Metode ini mampu meredam overshoot pada sistem dan mempercepat waktu respon (rise time) sistem dibandingkan metode yang lain. Sistem penghindar rintangan membutuhkan nilai overshoot yang kecil dan waktu respon yang tepat agar tidak terjadi gesekan maupun tumbukan. Hasil penelitian ini mendapatkan rise time (waktu tempuh) wahana untuk menghindari rintangan yaitu 4,7 detik dengan kecepatan terbang 0,6 m/s dan simpangan untuk sudut roll sebesar $14,27^{\circ}$, pitch sebesar $13,26^{\circ}$, dan yaw sebesar $9,87^{\circ}$ ketika melakukan manuver menghindari rintangan.
\end{abstract}

Kata kunci-UAV, Otonom, Halangan

Abstract
Quadrotor is one of UAV (Unmanned Aerial Vehicle) rotary wing aircraft type. Quadrotor has been widely used for various needs to military or civilian. Quadrotor can be operated manually by remote or autonomously. One of the difficulties of quadrotor operations is to avoid the obstacles before autonomous flying towards destination point. Therefore, an obstacle avoidance control system is required on quadrotor systems.

Linear Quadratic Regulator is a control system that produces an input value system from state value and feedback. State value is produced from translation and rotation. That input value then converted into pulse width modulation to control the speed of the brusless motor, and it's used to do obstacles avoidance manouver.

This method might reduce overshoot on the system and make response time (rise time) arrived faster than other methods. The obstacle avoidance system requires small overshoot value and an appropriate response time to avoid frictions or collisions. The result of this research is the rise time to avoid obstacles that reached 4,7 second with flight speed of 0,6 m/s and turns for roll angle equal to $14,27^{\circ}$, pitch equal to $13,26^{\circ}$, and yaw equal to $9,87^{\circ}$ while avoidance maneuvering obstacles.

Keywords-UAV, Autonomous, Friction 


\section{PENDAHULUAN}

$\mathrm{Q}$ uadrotor adalah salah satu dari jenis UAV (Unmanned Aerial Vehicle) yang memiliki empat buah rotor sebagai sumber penggerak. Pada awalnya, Quadrotor dimanfaatkan pada bidang militer [1]. Namun penggunaan quadrotor saat ini semakin luas karena banyak kalangan sipil memanfaatkan quadrotor untuk berbagai kebutuhan.

UAV didefinisikan sebagai wahana terbang tanpa pilot yang dapat terbang baik secara mandiri (otonom) dengan bantuan auto pilot atau dioperasikan dengan remote control dari jarak jauh. Salah satu kesulitan dari pengoperasian quadrotor ketika terbang secara mandiri adalah membuat quadrotor dapat bergerak fleksibel ketika terbang di tempat yang luas menuju suatu titik tujuan namun terdapat rintangan di depannya [2].

Sistem penghindar rintangan merupakan salah satu sistem yang banyak dikembangkan di berbagai misi Unmanned Vehicle (UV). Sistem ini berfungsi agar UV mampu menghindari rintangan yang ada di depannya sehingga UV mampu menyelesaikan misinya. Apabila tanggap waktu yang dibutuhkan sistem terlalu lambat dan terdapat overshoot yang tinggi untuk menghindari rintangan, maka UV dapat menumbuk maupun bergesekan dengan rintangan yang ada di depannya. Hal ini dapat mengakibatkan UV tidak mampu menyelesaikan misinya [3].

Oleh karena itu dibutuhkan sistem kendali yang handal untuk menghindari rintangan, agar quadrotor mampu bergerak secara fleksibel. Apabila ada rintangan di depan, quadrotor mampu melakukan manuver menghindar lebih dini sehingga tumbukan ataupun gesekan dapat dihindari. Sensor ultrasonik dapat digunakan untuk mengetahui jarak antara quadrotor dengan rintangan. Sensor ultrasonik juga digunakan untuk mengetahui ketinggian quadrotor dari permukaan tanah. Parameter ketinggian ini dibutuhkan agar quadrotor dapat mempertahankan ketinggian pada saat terbang.

Terdapat beberapa metode kendali yang telah diimplementasikan pada quadrotor, diantaranya PID (Propotional Integral Derivatif), Fuzzy, Ant Colony Optimization, LQR (Linear Quadratic Regulator), dan lain-lain. Metode PID berdasarkan tuning LQR digunakan untuk kendali sikap pada penerbangan quadrotor menghasilkan nilai overshoot yang tinggi dan memiliki tanggap waktu yang lambat [4].

LQR adalah perkembangan dari metode pole placement dan HJB (Hamiltonian Jacobi Belmann) dengan meregulasi state sistem menjadi nol dengan masukan seoptimal mungkin [5]. Hal ini bertujuan agar bisa meminimalisir overshoot dan mempercepat tanggap waktu.

\section{METODE PENELITIAN}

\subsection{Analisis Sistem}

Quadrotor menggunakan empat motor brushless dengan baling-baling (propeller) sebagai penggerak. Quadrotor dapat memiliki konfigurasi terbang plus (+) atau silang (x). Baling-baling quadrotor yang memiliki arah putaran searah diletakkan saling berseberangan. Hal ini bertujuan untuk menghindari terjadinya gerakan rotasi roll dan pitch yang tidak diinginkan jika wahana mengalami gangguan ketika hovering.

Setiap rotor pada quadrotor berperan dalam menghasilkan thrust dan torsi terhadap titik pusat rotasinya, sehingga hasilnya akan menimbulkan gaya angkat (lift) bagi quadrotor [6]. Keseimbangan kecepatan antara keempat rotornya harus tercapai, agar wahana mampu terbang mendekati stasioner. Oleh karena itu, wahana membutuhkan sistem kendali penerbangan yang baik.

Penelitian ini menggunakan quadrotor konfigurasi terbang silang (x) yang ditunjukkan pada Gambar 1 dengan menggunakan baling-baling 1 dan 2 pada posisi depan kanan dan belakang kiri yang berputar berlawanan arah jarum jam (counter clockwise) sedangkan balingbaling 3 dan 4 pada posisi depan kiri dan belakang kanan yang berputar searah jarum jam (clockwise).

IJEIS Vol. 7, No. 2, October $2017: 219-230$ 


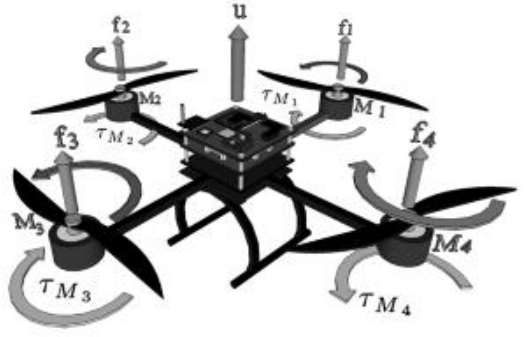

(a)

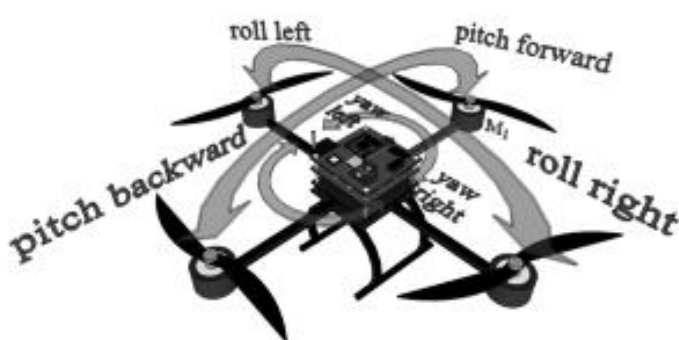

(b)

Gambar 1 Pergerakan dasar quadrotor (a) dan (b)

Quadrotor dapat terbang stabil jika sudut kemiringan memiliki toleransi maksimal 5\% dari total kemiringan wahana. Nilai dari sudut orientasi pitch dan roll diperoleh dari pembacaan IMU (Inertia Measurement Unit). Pembacaan IMU menggunakan metode sensor fusion DMP. Perhitungan dari akselerometer dan giroskop akan menghasilkan nilai sudut orientasi pitch dan roll dengan menggunakan library MPU6050 dengan sensor IMU gy-86, sedangkan perhitungan magnetometer yang menghasilkan nilai dari sudut orientasi yaw menggunakan library HMC5883L dengan kompas dari GPS (Global Positioning System) lea 6h [7].

GPS lea $6 \mathrm{H}$ juga digunakan sebagai masukkan untuk posisi $x$ dan $y$ yang memiliki ketelitian \pm 2 meter. Posisi $x$ dan $y$ ini digunakan untuk pengujian menuju ke titik tujuan. Nilai ketinggian dengan permukaan bumi dan jarak antara quadrotor dengan halangan didapatkan dari pembacaan sensor ultrasonik.

Batas nilai toleransi steady-state error untuk sistem linear orde 2 adalah 5\% dari rentang nilai yang dikendalikan [8]. Rentang nilai yang dikendalikan pada sudut pitch dan roll adalah $90^{\circ}$ dikarenakan sudut yang lebih besar dari $90^{\circ}$ merupakan kondisi wahana mengalami flip/terbalik, sehingga batas nilai steady state error sebesar $4,5^{\circ}$. Rentang nilai sudut yaw sebesar $180^{\circ}$ dikarenakan nilai pembacaan sensor maksimal sebesar $180^{\circ}$, sehingga batas nilai steady state error sebesar $9^{0}$.

Terdapat beberapa parameter yang dijadikan acuan untuk menentukan tingkat keberhasilan penelitian. Parameter keberhasilan dari sistem kendali quadrotor dapat diketahui dari beberapa kondisi berikut:

1. Nilai steady-state error di bawah batas toleransi 5\% dari nilai maksimal yaitu sebesar $90^{\circ}$ untuk sudut pitch dan roll yang dikendalikan dan sudut $180^{\circ}$ untuk sudut yaw, sehingga batas toleransi sudut pitch dan roll adalah $\pm 4,5^{\circ}$ sedangkan sudut yaw adalah $\pm 9^{0}$.

2. Rise time yang dihasilkan untuk sudut pitch dan roll kurang dari 2 detik dan untuk sudut yaw kurang dari 3 detik.

3. Maksimal overshoot untuk sudut pitch dan roll yang dihasilkan kurang dari $15 \%$ dan untuk yaw yang dihasilkan kurang dari $20 \%$.

4. Settling time yang dihasilkan untuk sudut pitch dan roll kurang dari 4 detik dan untuk sudut yaw kurang dari 6 detik.

5. Sistem dapat menjaga ketinggian terhadap referensi state (Xref) pada posisi $z$ yang ditentukan pengguna dengan nilai steady-state error di bawah batas toleransi yaitu \pm 5 $\mathrm{cm}$.

6. Sistem dapat mempertahankan posisi quadrotor dengan toleransi pergeseran terbang terhadap setpoint posisi $x$ dan $y$ adalah \pm 2 meter.

7. Sistem dapat mendeteksi adanya halangan di depan dengan jarak minimal $70 \mathrm{~cm}$, jarak maksimal $50 \mathrm{~cm}$ dan halangan di samping quadrotor dengan jarak minimal adalah 100 $\mathrm{cm}$ dan batas maksimal adalah $50 \mathrm{~cm}$. 


\subsection{Rancangan Sistem Kendali}

Kendali LQR merupakan pengembangan metode HJB (Hamilton-Jacobi-Bellman). Suatu persamaan dari suatu sistem dapat digambarkan dengan persamaan state space yang ditunjukkan pada Persamaan ((1).

$$
\begin{aligned}
& \dot{x}=A x+B u \\
& y=C x+D u
\end{aligned}
$$

Tujuan kendali LQR yaitu mencari gain matriks $\boldsymbol{K}$ sebagai feedback gain untuk mengoptimalkan sistem kendali [9]. Pemilihan kendali LQR sendiri dikarenakan metode kendali ini meminimalisir cost function pada Persamaan ((2). Kendali LQR bekerja berdasarkan matriks $\boldsymbol{Q}$ dan $\boldsymbol{R}$ yang tepat untuk dapat mempertahankan kestabilan terbang quadrotor. Proses pembobotan matriks $\boldsymbol{Q}$ dan $\boldsymbol{R}$ dilakukan untuk mendapatkan respon kendali sesuai dengan spesifikasi kendali yang diinginkan.

$$
\begin{gathered}
I=\int_{t^{0}}^{\infty}\left(x^{T} Q_{x}+u^{T} R_{u}\right) d t \\
K=R^{-1} B^{t} S \\
A^{T} S+S A-S B R^{-1} B^{T} S+Q=0
\end{gathered}
$$

Nilai $\boldsymbol{Q}$ berbanding lurus dengan nilai $S$ seperti yang ditunjukkan persamaan ((4), di mana nilai $\boldsymbol{S}$ adalah variabel bantu untuk menentukan nilai $\boldsymbol{K}$ dari persamaan Riccati. Nilai $\boldsymbol{S}$ ini sebanding dengan penguatan nilai $\boldsymbol{K}$ sesuai persamaan ((3), sehingga semakin besar nilai $\boldsymbol{Q}$ maka semakin besar pula nilai $\boldsymbol{K}$. Penalaan $\boldsymbol{Q}$ dan $\boldsymbol{R}$ dimulai dari nilai 1, kemudian akan ditambah atau dikurangi sesuai dengan kebutuhan sistem, namun konstanta $\boldsymbol{Q}$ dan $\boldsymbol{R}$ memiliki fungsi yang berlawanan, apabila nilai $\boldsymbol{R}$ besar, maka feedback menjadi tidak terlalu mempengaruhi sistem, oleh karena itu penalaan hanya dilakukan pada matriks $\boldsymbol{Q}$, di mana matriks $\boldsymbol{R}$ diberi nilai 1 agar nilai $\boldsymbol{R}$ tidak mempengaruhi kendali.

Sistem dapat mempertahankan kondisi nol atau tidak membentuk sudut roll $(\phi)$, pitch $(\theta)$, dan yaw $(\psi)$ dengan menyesuaikan referensi yang baru. Persamaan state space yang baru seperti yang ditunjukkan pada persamaan (5).

$$
\begin{gathered}
\dot{x}=A x+B\left(-K\left(x-x_{r e f}\right)\right) \\
y=C x
\end{gathered}
$$

Rancangan sistem kendali pada penelitian ini menggunakan 12 state. Sistem kendali diperlukan agar quadrotor dapat terbang sesuai dengan yang diinginkan. State-state tersebut terdiri dari :

1. Sudut roll $(\phi)$

2. Sudut pitch $(\theta)$

3. Sudut $\operatorname{yaw}(\psi)$

4. Kecepatan sudut roll $\left(\omega_{\phi}\right)$

5. Kecepatan sudut pitch $\left(\omega_{\theta}\right)$

6. Kecepatan sudut yaw $\left(\omega_{\psi}\right)$
7. Posisi $x(\mathrm{x})$

8. Posisi $y(\mathrm{y})$

9. Posisi $z(\mathrm{z})$

10. Kecepatan translasi $x(\mathrm{Vx})$

11. Kecepatan translasi $y(\mathrm{Vy})$

12. Kecepatan translasi $z(\mathrm{Vz})$

$\boldsymbol{u}$ merupakan sinyal kendali yang menjadi masukan proses dengan kalkulasi perkalian antara feedback gain dan state sistem yang dikendalikan seperti yang ditunjukkan pada persamaan ((6), di mana terdapat empat masukan kendali yaitu $\boldsymbol{u} \boldsymbol{l}$ yang merupakan masukan gaya vertikal, $\boldsymbol{u} \mathbf{2}$ masukan untuk torsi rotasi roll, $\boldsymbol{u} \mathbf{3}$ masukan untuk torsi rotasi pitch dan $\boldsymbol{u 4}$ masukan untuk torsi rotasi yaw.

$$
u=-K x
$$




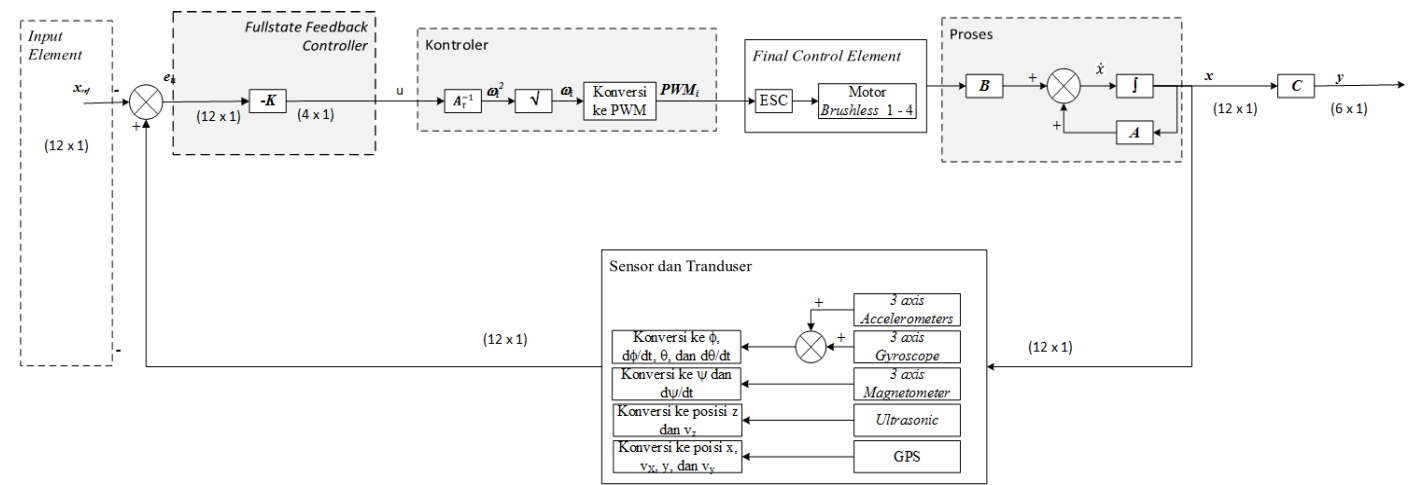

Gambar 2. Blok diagram kendali quadrotor

Pada $\boldsymbol{u} \boldsymbol{1}$ terdapat masukan gaya sebesar berat quadrotor agar quadrotor mampu mempertahankan keadaan stasioner saat terbang. Blok $\boldsymbol{A}, \boldsymbol{B}$ dan $\boldsymbol{C}$ adalah blok matriks karakteristik sistem sesuai dengan state space. Kendali ini kemudian digunakan untuk mengatur kecepatan masing-masing motor brushless.

Semakin besar nilai $\boldsymbol{K}$, semakin besar pula nilai $\boldsymbol{u}$ yang menjadi masukan sistem. Nilai $\boldsymbol{u}$ kemudian dikalikan dengan nilai $\boldsymbol{A}_{t}^{-1}$ untuk mencari kecepatan rotor $\omega$ kemudian dikonversi menjadi nilai PWM (Pulse Width Modulation) ke setiap rotor. Oleh karena itu dapat disimpulkan bahwa semakin besar nilai $\boldsymbol{Q}$, maka respon sistem yang bekerja akan semakin cepat dikarenakan perubahan masukan sistem $\boldsymbol{u}$ akan yang semakin besar sesuai dengan Gambar 2 .

\subsection{Arsitektur Sistem}

Pada penelitian ini komponen sensor yang digunakan adalah IMU, GPS, dan ultrasonik. Sensor IMU yang digunakan adalah IMU 10 Degree of Freedom (DOF) yang terdiri dari 3 DOF akselerometer, 3 DOF giroskop, 3 DOF magnetometer dan satu barometer. Gabungan sensor akselerometer dan giroskop tersebut juga dapat disebut sebagai sensor orientasi. Tujuan penggunaan sensor orientasi ini adalah untuk mengukur sudut dan kecepatan sudut roll dan pitch yang dibentuk oleh wahana terhadap sumbu bumi menggunakan teknik metode sensor fusion DMP (Digital Motion Processing).

Pada sensor magnetometer IMU diganti oleh kompas yang terdapat pada GPS untuk mengetahui arah quadrotor dan pembacaan sudut yaw. Sensor ultrasonik sebagai pengganti barometer pada IMU juga digunakan sebagai acuan ketinggian terbang quadrotor. Modul GPS digunakan sebagai navigasi untuk menentukan lokasi dan posisi quadrotor. Komponen Electronic Speed Control (ESC) berguna untuk melakukan pengaturan kecepatan motor brushless berdasarkan sinyal yang dikeluarkan oleh mikrokontroler dan sudah dirubah ke Pulse Width Modulation (PWM) [10]. Gambaran mengenai arsitektur sistem perangkat keras dapat dilihat pada Gambar 3.

Penelitian ini menggunakan dua tipe mikrokontroler yaitu master dan slave. Sebuah mikrokontroler master yang dipilih memiliki kecepatan pemrosesan yang tinggi untuk melakukan semua tugas yaitu Arduino Due, sedangkan mikrokontroler slave yang dipilih adalah Arduino Nano untuk membaca nilai jarak dari sensor ultrasonik untuk mendeteksi rintangan yang ada di hadapan maupun samping wahana. 


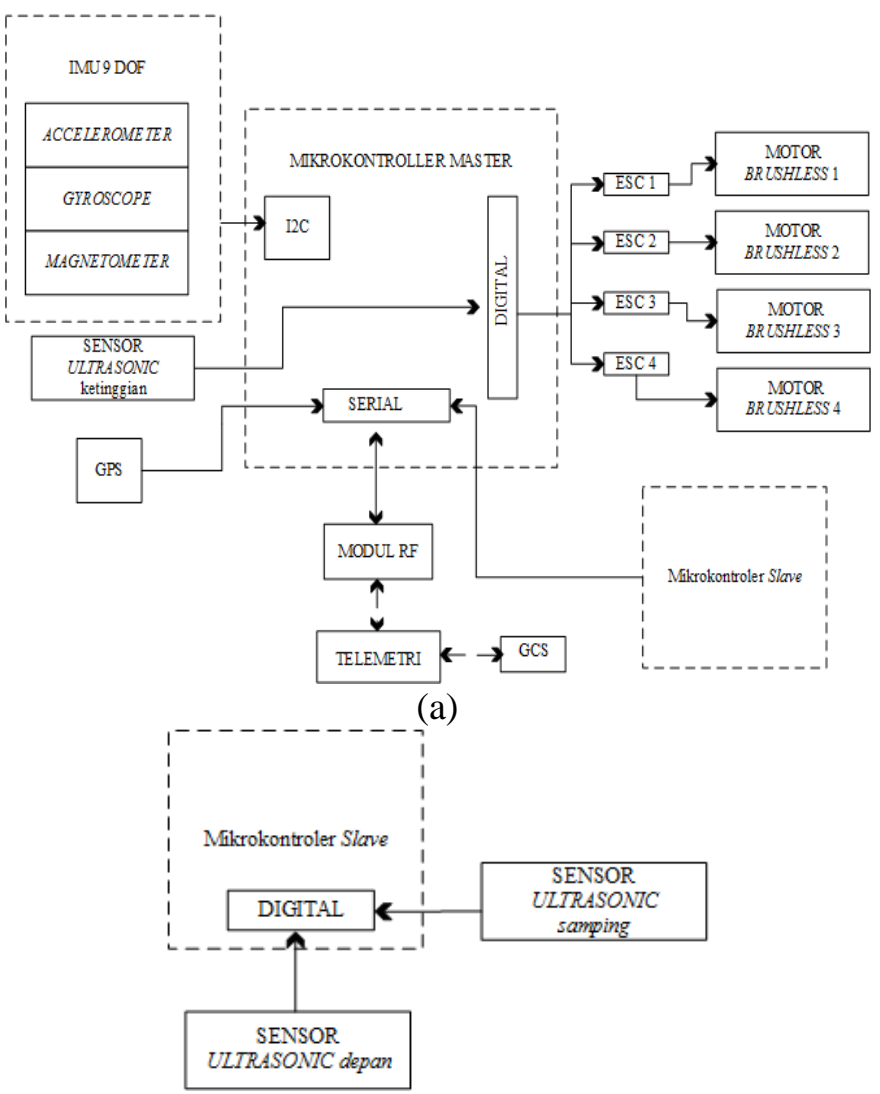

(b)

Gambar 3 Arsitektur sistem elektronis (a) dan (b)

Arduino Nano sebagai mikrokontroler slave dengan ukuran yang lebih kecil dan ringkas, memiliki memori yang cukup untuk melengkapi penggunaan mikrokontroler master. Hal tersebut dikarenakan library sensor jarak tidak dapat dioperasikan pada mikrokontroler master, sehingga membutuhkan mikrokontroler slave yang dapat mengoperasikan library sensor jarak agar sistem yang dijalankan tidak mendapatkan gangguan berupa delay. Komunikasi antara kedua mikrokontroler tersebut menggunakan komunikasi serial.

\section{HASIL DAN PEMBAHASAN}

\subsection{Hovering Quadrotor}

Pengujian sistem kendali LQR untuk gerakan hovering quadrotor diawali dengan uji di darat dan dilanjutkan dengan uji terbang. Tujuan dari pengujian-pengujian ini dilakukan untuk mendapatkan respon yang mendekati keadaan stationer. Respon sistem yang terdiri dari overshoot dan nilai steady state error pada hovering wahana menjadi dasar penentuan nilai $\boldsymbol{Q}$ hingga respon-respon sistem tersebut dapat diminimalisir.

Pada Gambar 4 dengan gangguan sebesar $30^{\circ}$ searah jarum jam menunjukkan hasil respon pada sudut roll dengan nilai $\boldsymbol{Q}$ sebesar 680 didapatkan rise time pada sistem sebesar 1 detik untuk menuju setpoint $0^{\circ}$ dengan overshoot sekitar $6,99^{\circ}$ serta memiliki nilai steady state error sebesar $1,7^{\circ}$ berlawanan arah jarum jam dan undershoot $3,79^{\circ}$ searah jarum jam dengan settling time selama 3,1 detik. 


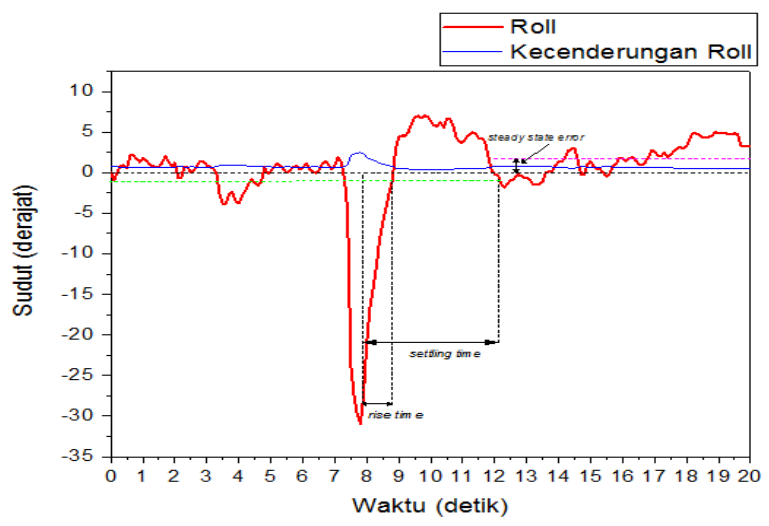

Gambar 4. Hasil pengujian respon roll $\boldsymbol{Q}$ sebesar 680

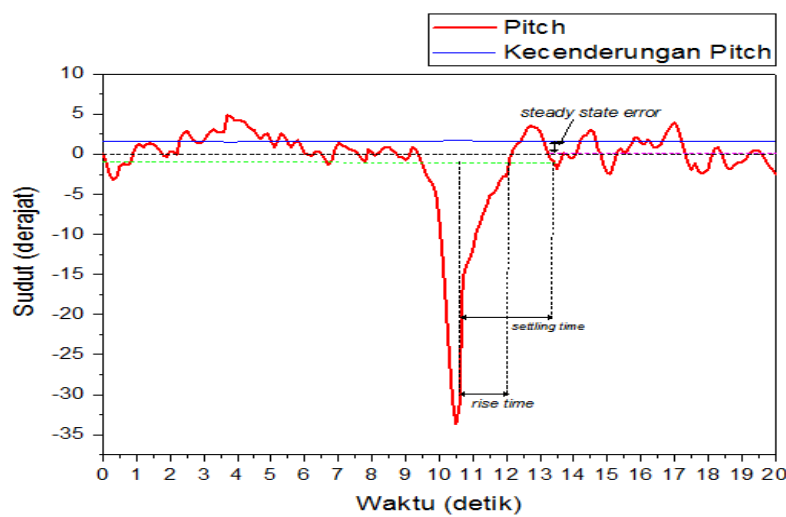

Gambar 5. Hasil pengujian pitch dengan $\boldsymbol{Q}$ sebesar 350

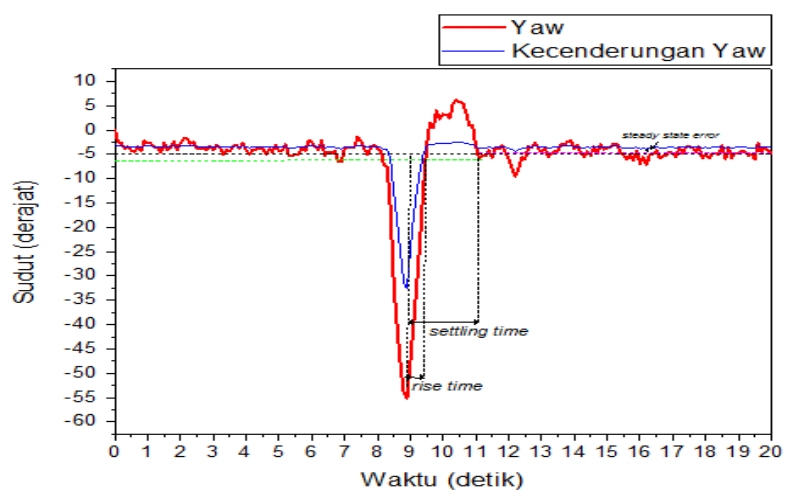

Gambar 6. Hasil pengujian yaw $\boldsymbol{Q}$ sebesar 1.850

Variasi pembobotan nilai $\boldsymbol{Q}$ untuk pitch menghasilkan nilai terbaik dengan pembobotan nilai $\boldsymbol{Q}$ sebesar 350 dengan nilai steady state error sebesar $0,14^{\circ}$ berlawanan arah jarum jam. Undershoot sebesar $3,41^{\circ}$ searah jarum jam dengan settling time selama 2,5 detik dan didapatkan rise time selama 1,6 detik dengan overshoot sekitar $3,57^{\circ}$ berlawanan arah jarum jam.

Pembobotan nilai $\boldsymbol{Q}$ untuk sudut yaw pada Gambar 6 menghasilkan hasil terbaik dengan pembobotan nilai $\boldsymbol{Q}$ sebesar 1850 dengan nilai steady state error sebesar $4,65^{\circ}$ searah jarum jam dan undershoot sebesar 9,54 ${ }^{\circ}$ searah jarum jam. Gambar 6 menunjukkan hasil respon pada sudut yaw dengan gangguan sebesar $50^{\circ}$ searah jarum jam didapatkan rise time pada sistem adalah 0,6 detik dengan overshoot mendekati $6,23^{\circ}$ berlawanan arah jarum jam dan settling time yang dibutuhkan untuk menuju ke setpoint adalah 2,1 detik. 
Pada pengujian variasi pembobotan $\boldsymbol{Q}$ ketika quadrotor yang terbang dengan simpangan mendekati 0 meter sepanjang sumbu $x$ dalam jangka waktu 20 detik didapatkan hasil terbaik yaitu pada pembobotan dengan nilai $\boldsymbol{Q}$ bernilai 5,5. Gambar 7 didapatkan hasil terbaik dengan steady state error quadrotor terbang pada posisi $x$ bergeser sejauh 0,3 meter ke arah utara dari Xref dan overshoot pada posisi sumbu $x$ sebesar 0,53 meter ke arah utara dengan undershoot adalah sebesar 0,16 meter ke arah selatan.

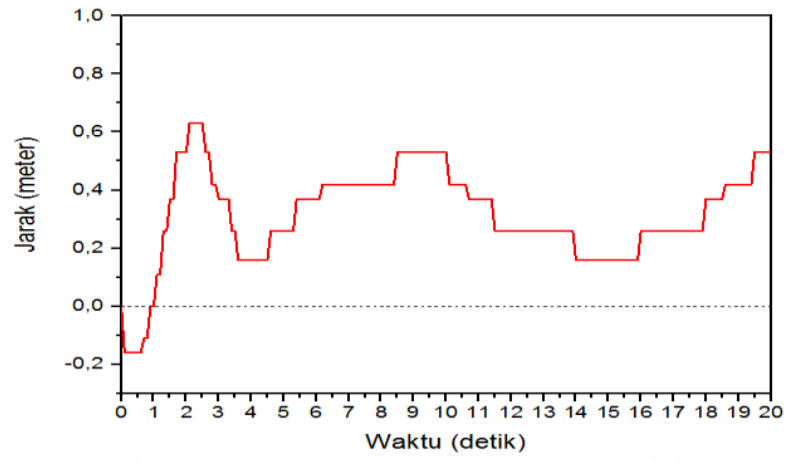

Gambar 7. Hasil pengujian mempertahankan posisi pada sumbu $x$

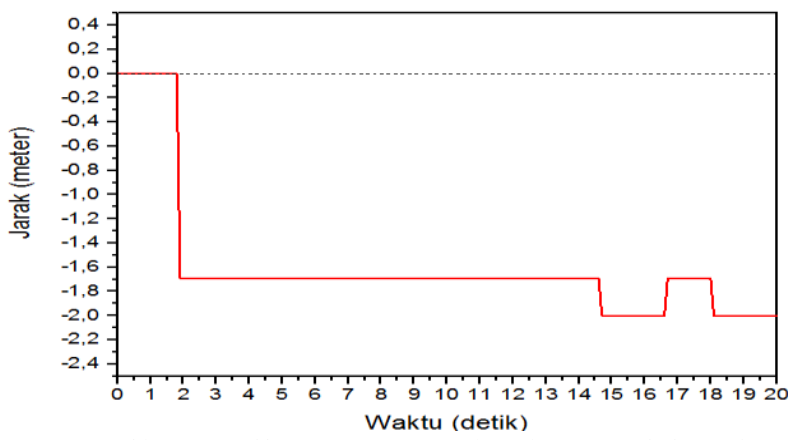

Gambar 8. Hasil pengujian mempertahankan posisi pada sumbu $y$

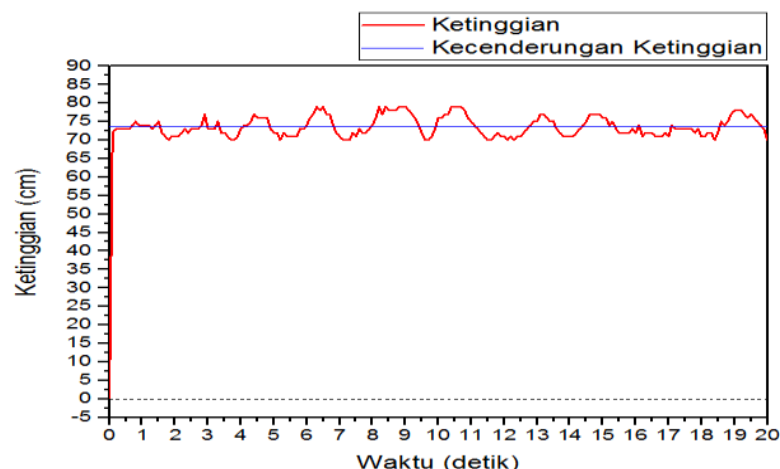

Gambar 9. Hasil pengujian sumbu $z$ pada ketinggian quadrotor

Pada pengujian variasi pembobotan $\boldsymbol{Q}$ didapatkan hasil dengan simpangan mendekati 0 meter sepanjang sumbu $y$ dalam jangka waktu 20 detik didapatkan hasil terbaik yaitu pada pembobotan dengan nilai $\boldsymbol{Q}$ sebesar 3,8. Gambar 8 didapatkan hasil terbaik dengan steady state error quadrotor terbang pada posisi y bergeser sejauh 1,69 meter ke arah barat dari Xref sedangkan undershoot sebesar 2 meter ke arah barat namun tidak terjadi overshoot pada posisi sumbu $y$.

Hasil Pengujian pada Gambar 9, hasil nilai $\boldsymbol{Q}$ sebesar 0,25 ditentukan sebagai nilai terbaik dikarenakan quadrotor mampu mempertahankan ketinggian diatas permukaan tanah

IJEIS Vol. 7, No. 2, October $2017: 219-230$ 
dengan steady state error adalah 71,74 $\pm 3,26 \mathrm{~cm}$. Hasil ini mendekati nilai ketinggian yang ditentukan yaitu $75 \mathrm{~cm}$ dengan overshoot pada sumbu $z$ sebesar $79 \mathrm{~cm}$ dan undershoot sebesar $70 \mathrm{~cm}$.

\subsection{Menghindari Rintangan}

Pengujian kendali LQR untuk menghindari rintangan dilakukan untuk mendapatkan respon sistem dengan mengamati sikap quadrotor ketika melakukan manuver menghindari rintangan di tengah jalur terbang wahana menuju titik tujuan yang sudah ditentukan sebelumnya. Pada pengujian ini wahana menempuh penerbangan sejauh 15 meter. Jarak yang didapatkan antara wahana dengan halangan berupa objek yang diletakkan di jalur terbang wahana sejauh 5 meter dari titik take off mampu dideteksi oleh pendeteksi rintangan ditunjukkan oleh Gambar 10(a) dan (b).

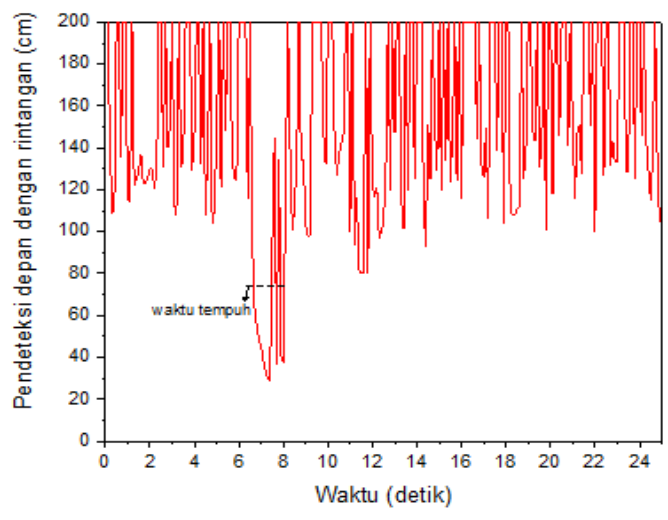

(a)

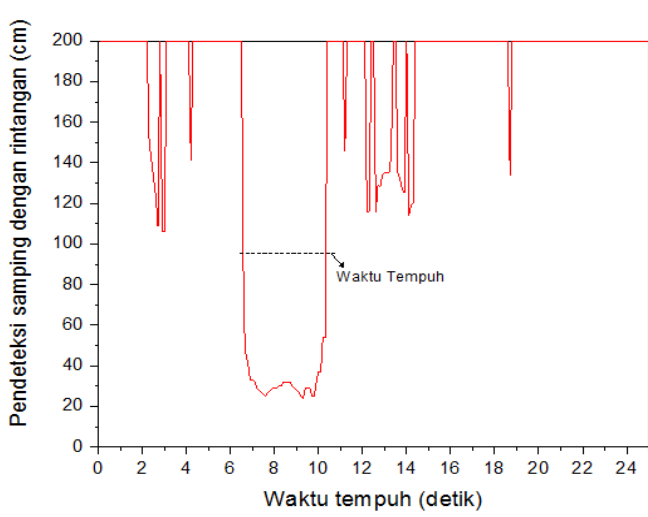

(b)

Gambar 10 Hasil pengujian pendeteksi rintangan depan ketika menghindari rintangan pada sumbu $x$ (a) dan samping pada sumbu $y$ (b)

Pada Gambar 10(a) menunjukkan pendeteksi rintangan mampu mendeteksi halangan di depan wahana pada jarak $55 \mathrm{~cm}$, dan pada Gambar 10 (b) menunjukkan pendeteksi rintangan mampu mendeteksi halangan di samping wahana pada jarak $63 \mathrm{~cm}$. Jarak dari luaran pendeteksi rintangan tersebut digunakan sebagai masukan untuk sistem kendali penghindar rintangan agar wahana melakukan manuver menghindari rintangan.

Quadrotor dapat menghindari rintangan di depan maupun sampingnya dengan rise time (waktu tempuh) yaitu 4,7 detik. Pengujian ini dilakukan dengan menggunakan elemen matriks $\boldsymbol{Q}$ pada gerakan sumbu $x$ dan $y$, sehingga wahana dapat melakukan manuver menghindari rintangan dengan kecepatan respon sistem dan kecepatan terbang wahana yang optimal ketika pendeteksi rintangan di bagian depan atau samping mendapatkan hasil luaran berupa jarak minimal antara wahana dengan rintangan agar tidak terjadi tumbukan maupun gesekan. 


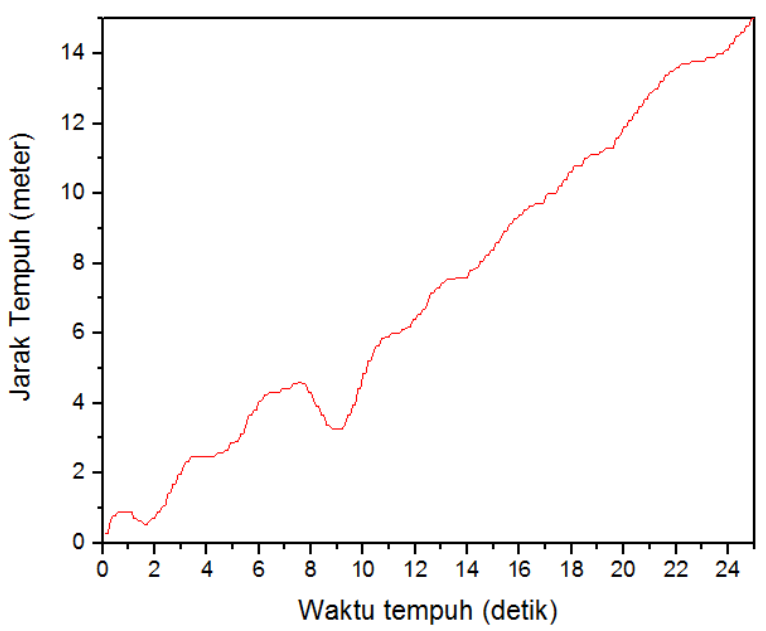

Gambar 11 Waktu tempuh quadrotor menuju titik tujuan

Pada Gambar 11, quadrotor dapat menuju ke titik tujuan yang telah ditentukan dengan rise time (waktu tempuh) yaitu 25 detik serta kecepatan terbang wahana sebesar $0,6 \mathrm{~m} / \mathrm{s}$. Hasil ini membuktikan bahwa quadrotor dapat terbang menuju titik tujuan dengan jarak 15 meter dari titik awal takeoff sepanjang sumbu $x$ dan mampu menghindari rintangan dengan kecepatan terbang yang optimal.

Pada penelitian ini terdapat gangguan sensing dari lingkungan maupun ketepatan GPS, pada saat itu wahana mulai menyimpang dari setpoint awal. Penyimpangan ini terus berlanjut walaupun wahana bergerak secara horisontal pada sumbu $\mathrm{x}$, sehingga seperti pada pengujian sebelumnya, posisi wahana tidak tepat pada titik tujuan yang telah ditentukan sebelumnya, hal ini dapat dikarenakan karena pergeseran dari manuver menghindari rintangan.

Pengujian manuver menghindari rintangan, membuktikan bahwa quadrotor mampu kembali ke jalurnya untuk melanjutkan terbang ke titik tujuan dengan simpangan maksimal untuk sudut roll sebesar $14,27^{\circ}$, pitch sebesar $13,26^{\circ}$, dan yaw sebesar $9,87^{\circ}$ yang ditunjukkan pada Gambar 12. Besarnya penyimpangan yang berupa pergeseran yang tidak diinginkan ini tidak sebesar gangguan sensing yang diterima.

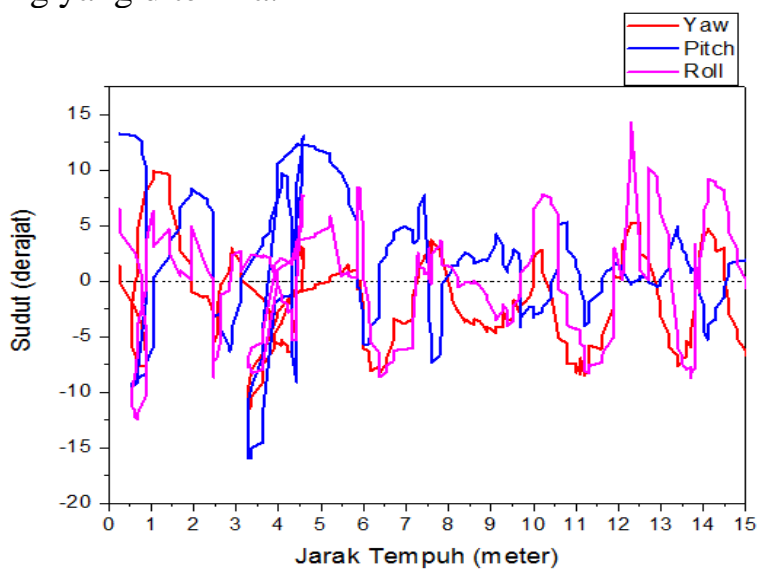

Gambar 12 Hasil pengujian hovering quadrotor melakukan manuver menghindari rintangan

Hal ini disebabkan wahana dengan kendali Linear Quadratic Regulator masih mampu melawan gangguan-gangguan tersebut. Apabila gain $\boldsymbol{K}$ ditingkatkan atau dikurangkan kembali melalui penalaan hovering quadrotor matriks $\boldsymbol{Q}$, wahana dapat mencapai setpoint. Namun wahana tetap sulit untuk mempertahankan keadaan tersebut. 
Pembobotan nilai $\boldsymbol{Q}$ yang diberikan mampu membuat wahana mencapai keadaan tunak walaupun masih terdapat simpangan maupun osilasi yang dikarenakan gangguan dari lingkungan maupun getaran dari motor brushless, hal ini masih dalam batas toleransi sehingga membuktikan bahwa kendali LQR mampu mempercepat rise time (waktu tempuh) untuk mencapai tujuan yang telah ditentukan sehingga kinerja sistem dapat optimal dengan overshoot dan undershoot yang kecil sesuai dengan spesifikasi sistem.

Pengujian dengan penalaan nilai $\boldsymbol{Q}$ yang kecil saat wahana melakukan manuver menghindar membuktikan bahwa sistem kendali LQR dapat meminimalkan cost function yang dibutuhkan untuk mempertahankan posisi dan ketinggian. Cost function yang kecil dapat mengurangi tenaga yang dibutuhkan dalam melakukan manuver menghindari rintangan.

\section{KESIMPULAN}

Kesimpulan yang dapat diambil dari penelitian yang telah dilakukan adalah Quadrotor mampu menghindari rintangan pada jalur terbangnya menggunakan konsep Linear Quadratic Regulator (LQR) secara otonom. Hasil pengujian kendali LQR pada gerak sudut roll, pitch, dan yaw mampu mempertahankan kestabilan quadrotor dengan nilai rise time, settling time, steady state error, overshoot maupun undershoot sesuai dengan spesifikasi sistem.

Kecepatan terbang quadrotor yang optimal pada saat melakukan manuver menghindari rintangan yaitu $0,6 \mathrm{~m} / \mathrm{s}$ dengan rise time (waktu tempuh) menghindari rintangan yaitu 4,5 detik. Manuver menghindari rintangan berhasil dilakukan tanpa mengalami gesekan maupun tumbukan antara quadrotor dan rintangan, sehingga wahana mampu mencapai titik tujuan yang telah ditentukan.

\section{SARAN}

Pada penelitian ini masih terdapat beberapa hal yang perlu disempurnakan. Saran-saran yang dapat digunakan untuk menyempurnakan penelitian selanjutnya adalah perlu adanya penelitian lanjutan tentang sistem kendali penghindar rintangan menggunakan metode LQR dengan objek yang berjalan.

Peningkatan tentang arsitektur sistem elektronik dengan kapasitas memori yang lebih besar dan kecepatan proses yang lebih cepat, sehingga penggunaan mikrokontroler hanya satu unit saja.

\section{UCAPAN TERIMA KASIH}

Penulis mengucapkan terima kasih kepada seluruh keluarga E-drones dan Gamaforce yang telah mendukung dan membantu dalam penelitian ini.

\section{DAFTAR PUSTAKA}

[1] M. D. Schmidt, "Simulation and Control of A Quadrotor Unmanned Aerial Vehicle," University of Kentucky, 2011.

[2] S. Bouabdallah, M. Becker, V. de Perrot, and R. Siegwart, "Toward obstacle avoidance on quadrotors," XII Int. Symp. Dyn. Probl. Mech., no. Diname, pp. 1-10, 2007.

[3] A. P. S. Putra and A. Dharmawan, "Implementasi Metode PID FUZZY untuk Menghindari Tumbukan pada Quadrotor," Universitas Gadjah Mada, 2015.

[4] F. Rozani and A. Dharmawan, "Implementasi Sistem Kendali PID pada Quadrotor dengan Pendekatan Penalaan LQR," Universitas Gadjah Mada, 2016.

[5] B. Panomrattanarug, K. Higuchi, and F. Mora-Camino, "Attitude control of a quadrotor aircraft using LQR state feedback controller with full order state observer," Proc. SICE Annu. Conf., pp. 2041-2046, 2013.

[6] J. Domingues, "Quadrotor prototype," Inst. Super. Tec. Univ. Tec. ..., no. October, p. 
129, 2009.

[7] R. Prahasta and A. Dharmawan, "Implementasi Metode LQR (Linear Quadratic Regulator) pada Pengendali Terbang Quadrotor untuk Kestabilan Sikap Pesawat," Universitas Gadjah Mada, Yogyakarta, Indonesia, 2016.

[8] K. Ogata, Modern Control Engineering Fifth Edition. New Jersey, USA: Prentice Hall, 2010.

[9] Z. Shulong, A. Honglei, Z. Daibing, and S. Lincheng, "A new feedback linearization LQR control for attitude of quadrotor," in 2014 13th International Conference on Control Automation Robotics \& Vision (ICARCV), 2014, vol. 2014, no. December, pp. $1593-1597$.

[10] A. Dharmawan and I. F. Arismawan, "Sistem Kendali Penerbangan Quadrotor pada Keadaan Melayang dengan Metode LQR dan Kalman Filter," IJEIS (Indonesian J. Electron. Instrum. Syst., vol. 7, no. 1, p. 49, Apr. 2017 [Online]. Available: https://jurnal.ugm.ac.id/ijeis/article/view/15262. [Accessed: 31-May-2017] 